or too time-consuming for good honours students. But a rather more sophisticated approach is required of the reader in chapter eleven ("Gradients in Cells") and chapter sixteen. J. N. Agar

\section{RARE EARTH SPECTRA}

\author{
Spectra and Energy Levels of Rare Earth lons in Crystals \\ By G. H. Dieke. Pp. xi +401 . (Wiley (Interseience): \\ London, January 1969.) 131s.
}

INTEREST in the rare earth ions has recently been stimu. lated by the invention of the laser, by the development of methods for the purification of the rare earth elements, and by advances in techniques for computing their spectra and energy levels.

Much of our systematized knowledge of rare earth spectra we owe to the late Professor G. H. Dieke, and the book he and his collaborators, H. M. and Hannah Crosswhite, have now produced is the most useful collection of new and previously published data since the compilation of M. A. El'yashevich in 1953. There are five chapters on experimental techniques and six chapters on methods of calculation of spectra and energy levels; these chapters are somewhat brief and the theoretical chapters are not for the beginner. The largest chaptor in the book is a review of the empirical data, but throughout the book a wealth of data is to be found. Some of the photographic plates illustrated would have been more useful if a frequency scale had been included. The eaptions to Figs. 13 and 15, and to Figs. 14 and 16, have been swopped around by mistake ; the reference to Fig. 15 on page 47 should have been to Fig. 13, and that to Fig. 14 on page 53 should have been to Fig. 16 .

Roy E. Ballard

\section{SYSTEMS ENGINEERING}

\section{Servomechanisms}

An Introduction to the Practice and Theory of ClosedLoop Position-Control Systems, with an Account of Methods of Data Transmission and Computation. Second edition. By P. L. Taylor. Pp. xvi +424 . (Longmans: London, January 1969.) 70s.

SERVOMECHANISMS wero first systematized as a subject as a result of military engineering developed in the last war. At the time when the first edition of Taylor's book was written (1960), opportunity had occurred for substantial rationalization in this subject matter. This volume has the same object as the original edition, that of providing a self-sufficient textbook for degree and degree-level students who wish to specialize in control and systems engineering, and it shows clear signs of the author's substantial experience as a teacher of electrical engineering and control subjects of several years standing. In bringing the work up to date, the author has rewritten one chapter only, although he admits to numerous corrections; the main changes are the insertion of material related to the performance of transistor and thyristor cireuits. 'This chapter, chapter eight, defines the thyristor and considers thyristor control circuits and thyristor cirevits for a.c. and d.c. supplies, each with a d.c. load, as well as arrangements for driving a.c. motors.

The book is indeed self-sufficient from a student's point of view. There is thus available to the reader a very largo section, one third of the book, which deals with the properties of linear systems, complex variable theory, Laplace transform, transient and steady-state harmonic response, all as introduction to the transient response of closed loop systems and the steady-state harmonic response of closed loop systems. Unfortunatoly, as in the first volume, not a great deal of attention has been paid to the difficult and pervasive problems of non-linearity.

The most serious criticism is undoubtedly that the subject has moved on a great deal in 8 or 9 years. The extent of computer simulation and of techniques for solution which depend on the use of the computer are now widespread and receive scant attention. It is this lack of mention of current methods which appears to be a major limitation, although this does nothing to detract from the value of the work as an undergraduate, and to some extent an MSc-level, textbook. It is in this sense that the book is very useful because it is very comprehensive within the acceptable definition of "servomechanisms"; certainly the first reader of the subject would not have to go far beyond this book for his background theory. It is when one considers the systems engineering content of the various MSc courses in control and systems engineering which have developed over the period of the life of the first edition that one doubts the book's general validity.

Servomechanisms is excellently written with an abundance of numerical problems, all highly illustrative. Descriptive material is very clear and the bibliography is extensive within the field chosen by the author. The price has risen 70 per cent since the first cdition, but it is basically good value. ('OLIN ADAMSON

\section{OPERATIONS RESEARCH}

\section{Introduction to Operations Research}

By A. Kaufmann and R. Faure. Translated by Henry C. Sneyd. (Mathematics in Scienee and Engineering, Vol. 47.) Pp. xi +300 . (Academic Press: New York and London, September 1968.) 135s $4 d$.

THERE is by now a large spectrum of books on operations research, stretching from books on principles and strategy and advice for managers, to books on models and mathematical techniques, the latter often of a rather sophistieated kind. This book occupies a place in this spectrum which was previously unoceupied. It is easily read by the non-specialist and the industrial manager because each chapter, which is essentially designed to illustrate a mathematical technique, starts with a simple practical real situation, formulates slowly and carefully the problem, and then indicates, via some inild mathematics, how the problem may be solved. But it is also of interest to the mathematician who wants to learn something about what operations research deals with, what branches of mathematies are relevant in this applied field, and just, how the mathematical method is used in relation to the practical problem at hand. Thus the book will be of value both to the student contemplating a career in operations research and to the industrial manager or director who wishes to set up a degree of operations research in his organization.

It might be useful to indicate briefly the wide variety of problems discussed and solved. These include problems of stock, allocation, manufacture, delay (queueing), transport, assignment, replaccment and scheduling. There are also sections dealing, mildly, with theory of games, Boolean algebra, programming and the theory of graphs.

For the mathematician, perhaps the most interesting parts of the book aro those showing the importance of combinatorial mathematics. Who would have thought that, in the mathematical study of certain circus acts, or more serious problems of production scheduling, Hamiltonian paths in a network and equivalence classes of matrices would prove to be of great importance? Any mathematician who would like to be introduced to a new branch of applied mathematics should read this book.

T. S. ( KODDARD 